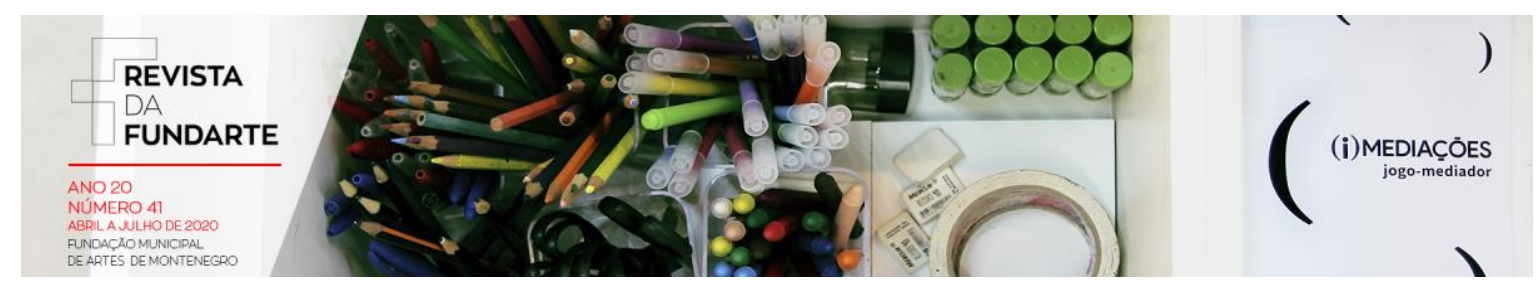

\title{
FORMAÇÃO E CAPACITAÇÃO EM DANÇA DE PROFESSORES DE ARTES E EDUCAÇÃO FÍSICA DO ENSINO FUNDAMENTAL
}

\author{
Laura Ruaro Moraes \\ Martina Bevilacqua \\ Taiana Souza Alves \\ Flávia Pilla do Valle \\ Aline Nogueira Haas
}

DOI: http://dx.doi.org/10.19179/2F2319-0868.732

MORAES, Laura Ruaro; BEVILACQUA, Martina; ALVES, Taiana Souza; VALLE, Flávia Pilla do; HAAS, Aline Nogueira. Formação e capacitação em dança de professores de artes e educação física do Ensino Fundamental. Revista da FUNDARTE. Montenegro, p.01-17, ano 20, oㅜ 41, Abril/Junho de 2019.

Disponível em: http://.seer.fundarte.rs.gov.br/index.php/RevistadaFundarte/index> 30 de junho de 2020. 


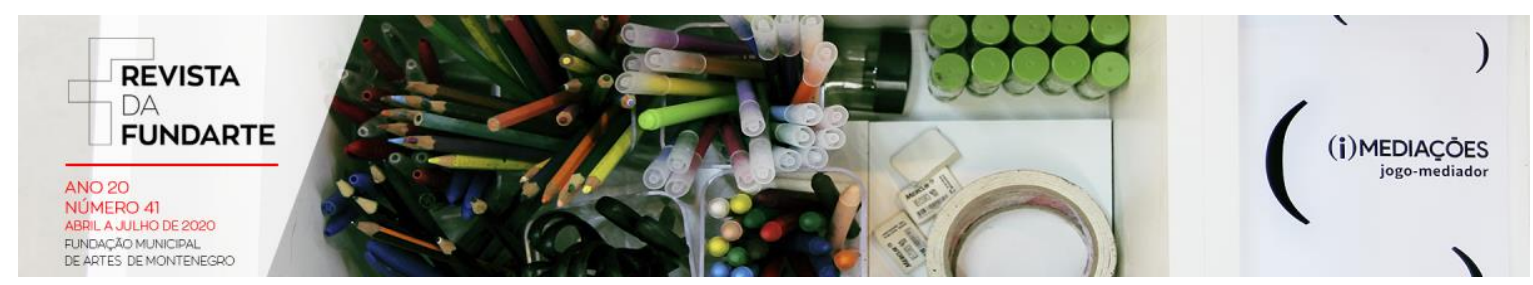

\title{
FORMAÇÃO E CAPACITAÇÃO EM DANÇA DE PROFESSORES DE ARTES E EDUCAÇÃO FÍSICA DO ENSINO FUNDAMENTAL
}

\author{
Laura Ruaro Moraes ${ }^{1}$ \\ Martina Bevilacqua² \\ Taiana Souza Alves ${ }^{3}$ \\ Flávia Pilla do Valle 4 \\ Aline Nogueira Haas ${ }^{5}$
}

Resumo: O objetivo desse estudo foi identificar a formação e a capacitação em dança do professor de Arte e de Educação Física das Escolas Municipais de Ensino Fundamental de Porto Alegre, RS. Os sujeitos de pesquisa foram 91 professores de 22 escolas municipais, sendo 36, da disciplina de Arte; e, 55, da Educação Física. O instrumento de coleta de dados foi um questionário de perguntas fechadas e abertas. A análise dos dados ocorreu através da determinação de duas categorias: perfil do professor de dança: formação e capacitação; e, perfil do professor de dança: atuação na escola. Os resultados obtidos refletiram uma realidade específica de uma época, demonstrando que os egressos de licenciaturas em dança ainda não estavam inseridos no ensino fundamental de escolas municipais de Porto Alegre.

Palavras-chave: Dança; Dança Educação; Professor.

\section{DANCE TRAINING OF ARTS AND PHYSICAL EDUCATION TEACHERS FROM ELEMENTARY SCHOOL}

\begin{abstract}
The propose of the study was to identify the dance training of Arts and Physical Education Teachers at Municipal Elementary School in Porto Alegre, RS. The participants were 91 teachers from 22 Municipal Schools, 36 from Arts; 55 from Physical Education. The instrument was a questionnaire with close-ended and open-ended questions. The data analysis occur though two categories: dance teacher profile: training; and dance teacher profile: school work. The results reflect a specific period of time, showing that graduates of dance degree were not included in the Municipal Elementary Schools of Porto Alegre.
\end{abstract}

Keywords: Dance; Dance education; Teacher.

\footnotetext{
${ }^{1}$ Licenciada em Dança, Mestre em Ciências do Movimento Humano.

2 Licenciada em Dança

3 Licenciada em Dança

${ }^{4}$ Licenciada em Educação Física; Doutora em Educação.

${ }^{5}$ Licenciada em Dança; Doutora em Ciências do Movimento Humano; Pós-doutorado na área da "Dance Science" University of Wolverhampton, Reino Unido.
}

MORAES, Laura Ruaro; BEVILACQUA, Martina; ALVES, Taiana Souza; VALLE, Flávia Pilla do; HAAS, Aline Nogueira. Formação e capacitação em dança de professores de artes e educação física do Ensino Fundamental. Revista da FUNDARTE. Montenegro, p.01-17, ano 20, no 41, Abril/Junho de 2019.

Disponível em: http://.seer.fundarte.rs.gov.br/index.php/RevistadaFundarte/index> 30 de junho de 2020. 


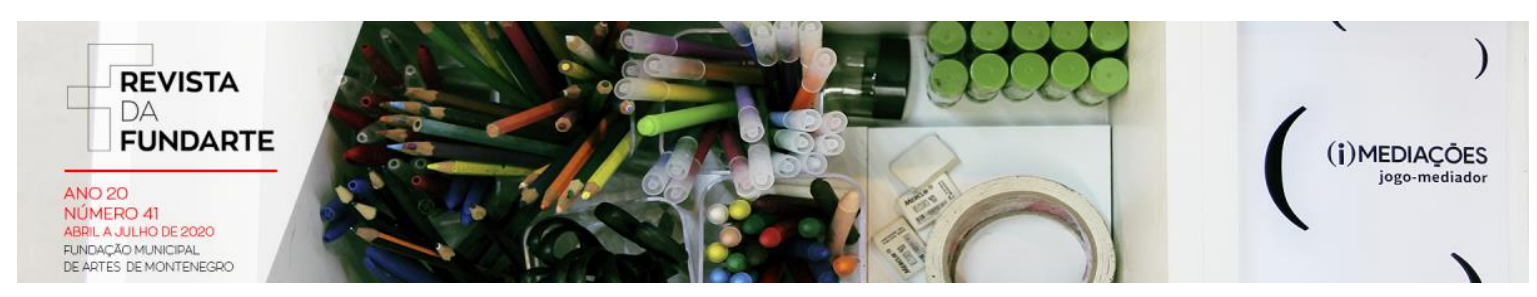

\section{INTRODUÇÃO}

Nas últimas décadas, a dança tem passado por um processo de legitimação como linguagem artística a ser ministrada na escola. Essa legitimação se deu tanto por meio da criação de novos cursos de formação de professores,quanto por meio da sua presença na legislação e documentos oficiais.

A Lei de Diretrizes e Bases da Educação Nacional-LDB,Lei n`9.394/1996 (BRASIL, 1996), fixa as diretrizes e bases da educação nacional e prevê o ensino das artes como conteúdo obrigatório na escola básica. Em 2016, foi aprovada a Lei n 13.278, que altera o $\S 60$ do art. 26 da LDB: "As artes visuais, a dança, a música e o teatro são as linguagens que constituirão o componente curricular de que trata $0 \S$ 2o deste artigo" (BRASIL, 2016). Logo, a partir dessa lei, a dança, como uma das linguagens das artes, faz parte do currículo dos diversos níveis de educação básica.

De acordo com os Parâmetros Curriculares Nacionais - PCN's (BRASIL, 1997), a dança está incluída na escola nas disciplinas de Educação Física e Artes, sendo tarefa dos professores dessas disciplinas ministrar esse conteúdo. $\mathrm{Na}$ disciplina das artes a dança está inserida com finalidade de desenvolver a competência estética e artística dos alunos, produzindo trabalhos pessoais e grupais para que possam, apreciar, desfrutar, valorizar e julgar os bens artísticos de distintos povos e culturas produzidos ao longo da história e na contemporaneidade. $\mathrm{Na}$ Educação Física, está inserida com o objetivo de proporcionar lazer, expressão de sentimentos, afetos e emoções.

Nos Parâmetros Curriculares Nacionais, nos blocos de conteúdo da educação física, a dança está incluída em "Atividades Rítmicas e Expressivas". Embora compreendida como um dos temas da cultura corporal, a dança aparece na forma de "atividades" ritmadas juntamente com as brincadeiras cantadas [...] $O$ documento ressalta ainda que 0 enfoque dado a "Atividades Rítmicas e Expressivas" é complementar ao conteúdo "Dança" do documento de arte (MORANDI, 2006, p.101).

Além da LDB e dos PCN's, a dança é legitimada no novo documento oficial da

MORAES, Laura Ruaro; BEVILACQUA, Martina; ALVES, Taiana Souza; VALLE, Flávia Pilla do; HAAS, Aline Nogueira. Formação e capacitação em dança de professores de artes e educação física do Ensino Fundamental. Revista da FUNDARTE. Montenegro, p.01-17, ano 20, oㅡ 41, Abril/Junho de 2019.

Disponível em: http://.seer.fundarte.rs.gov.br/index.php/RevistadaFundarte/index> 30 de junho de 2020. 


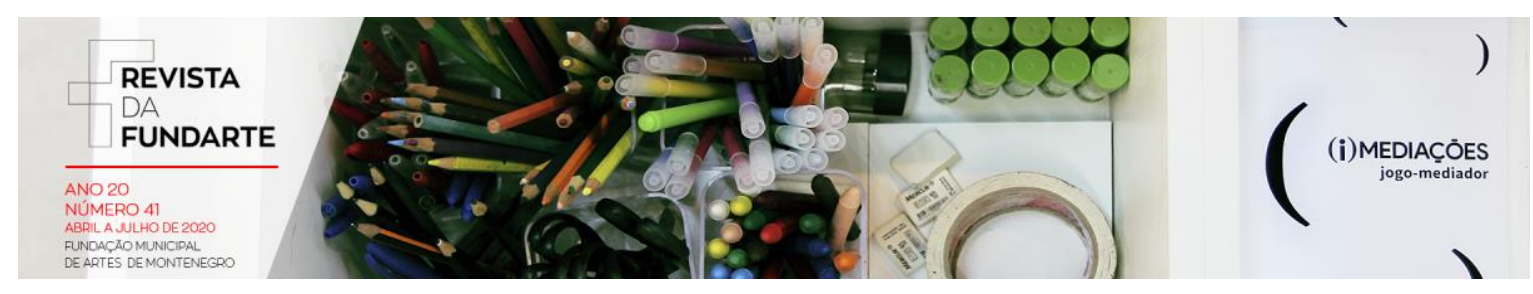

Base Nacional Comum Curricular (BNCC) que consiste em "um documento de caráter normativo que define o conjunto orgânico e progressivo de aprendizagens essenciais que todos os alunos devem desenvolver ao longo das etapas e modalidades da Educação Básica" (BRASIL, 2017, p. 7). Neste documento a dança aparece novamente citada como linguagem das artes e como objeto de conhecimento da educação física. A questão da dança estar inserida nessas duas propostas já foi objeto de embate. Se por um lado há uma Licenciatura em Dança que vê essa arte em profundidade, por outro a Licenciatura em Educação Física considera a dança como um aspecto da cultura corporal.

Souza, Pereira e Icle (2015) apontam que o Rio Grande do Sul, possui seis cursos de graduação em dança, mantidos por cinco diferentes universidades: Universidade Estadual do Rio Grande do Sul/UERGS (licenciatura); Universidade Federal do Rio Grande do Sul/UFRGS (licenciatura); Universidade Federal de Pelotas/UFPEL (licenciatura); Universidade Luterana do Brasil/ULBRA (licenciatura); e, Universidade Federal de Santa Maria/UFSM (licenciatura e bacharelado). Porém, atualmente, o curso de licenciatura em Dança da ULBRA encontra-se com suas atividades encerradas. O surgimento da maior parte destes cursos se deu pela implementação do REUNI, programa criado pelo Governo Federal com o objetivo de incentivar à expansão da universidade pública (BRASIL, 2007).

Ainda assim, existem poucos estudos que buscam compreender quem é o professor que ensina dança nas Escolas Municipais de Porto Alegre ${ }^{6}$, Rio Grande do Sul, como ela é ensinada e onde ocorrem essas aulas. Em busca realizada em banco de dados, somente foi encontrado o estudo de Massutti (2003) com professores de Educação Física da Rede Municipal de Porto Alegre, RS, visando identificar a presença ou não da dança enquanto conteúdo desenvolvido nas aulas

\footnotetext{
${ }^{6}$ Os anos iniciais da Rede Municipal de Escolas Fundamentais de Porto Alegre possui professores que atuam especificamente na área de Artes e Educação Física, caracterizando-se por uma pluridocência desde o primeiro ano do Ensino Fundamental.
}

MORAES, Laura Ruaro; BEVILACQUA, Martina; ALVES, Taiana Souza; VALLE, Flávia Pilla do; HAAS, Aline Nogueira. Formação e capacitação em dança de professores de artes e educação física do Ensino Fundamental. Revista da FUNDARTE. Montenegro, p.01-17, ano 20, oㅡ 41, Abril/Junho de 2019.

Disponível em: http://.seer.fundarte.rs.gov.br/index.php/RevistadaFundarte/index> 30 de junho de 2020. 


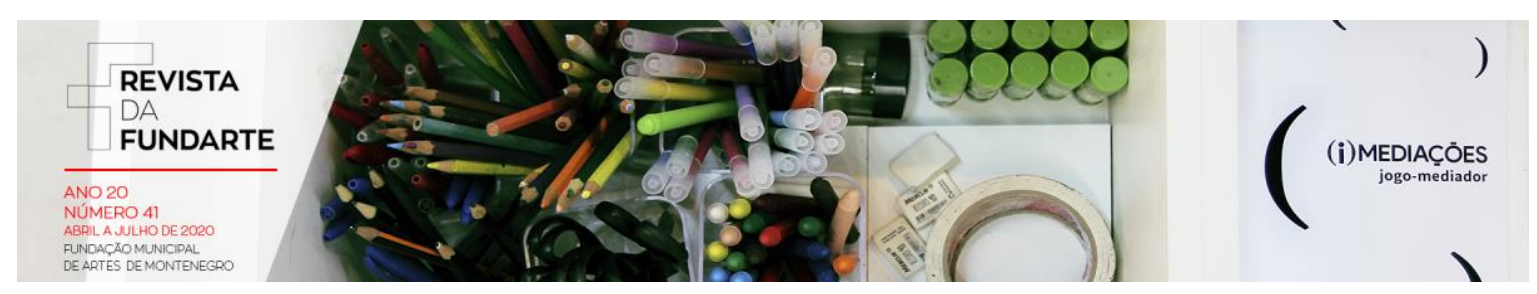

desses professores.

Dessa forma, o objetivo desse estudo foi identificar a formação e a capacitação em dança dos professores que ministram atividades relacionadas à dança nas disciplinas de Arte e de Educação Física das Escolas Municipais de Ensino Fundamental de Porto Alegre, RS. Para tanto, foram estabelecidos os seguintes questionamentos: Qual é a formação e capacitação em dança dos professores das disciplinas de Arte e Educação Física das Escolas Municipais de Ensino Fundametal de Porto Alegre, RS? A dança está sendo ensinada nestas disciplinas e inserida nesse no contexto escolar?

\section{CAMINHOS METODOLÓGICOS}

Esta pesquisa foi caracterizada por ser do campo descritivo e de cunho qualiquantitativa (GAYA et al., 2008; THOMAS; NELSON; SILVERMAN, 2012).Este estudo foi submetido ao Comitê de Ética em Pesquisa da Universidade Federal do Rio Grande do Sul e foi aprovado sob o número do parecer 18247.

Para a realização da pesquisa, foram contatadas 48 Escolas de Ensino Fundamental do Município de Porto Alegre, Rio Grande do Sul, das zonas norte, sul, leste e oeste; porém, 22 Escolas aceitaram participar do estudo. Os sujeitos de pesquisa foram 91 professores das escolas participantes, sendo 36 professores da disciplina de Arte (40\% da amostra); 55, da Educação Física (60\% da amostra).

$\mathrm{O}$ instrumento de coleta de dados foi um questionário de perguntas fechadas e abertas, elaborado especificamente para esta pesquisa e aplicado com o intuito de determinar alguns aspectos da formação e capacitação do professor das Escolas de Ensino Fundamental da Rede Municipal de Porto Alegre, RS, que trabalha com dança com as disciplinas de Arte e de Educação Física. Esse instrumento serviu para realizar um mapeamento das características desse professor (sexo, idade, etc.), buscando verificar sua formação, experiência, capacitação, e, também, se trabalha ou não com dança em suas aulas.

MORAES, Laura Ruaro; BEVILACQUA, Martina; ALVES, Taiana Souza; VALLE, Flávia Pilla do; HAAS, Aline Nogueira. Formação e capacitação em dança de professores de artes e educação física do Ensino Fundamental. Revista da FUNDARTE. Montenegro, p.01-17, ano 20, n 41, Abril/Junho de 2019.

Disponível em: http://.seer.fundarte.rs.gov.br/index.php/RevistadaFundarte/index> 30 de junho de 2020. 


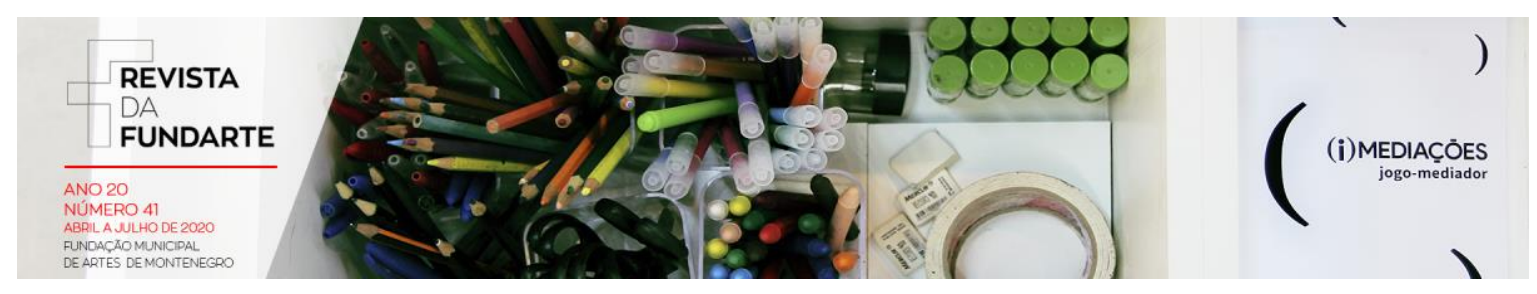

Para a seleção dos sujeitos de pesquisa, foi realizado contato por e-mail ou via telefone, com todas as Escolas Municipais de Ensino Fundamental de Porto Alegre, RS. Após o retorno das escolas, era agendada uma visita a mesma para a apresentação da pesquisa aos responsáveis e entrega dos documentos da pesquisa: carta da SMED de autorização para a realização da pesquisa, carta convite aos professores, termo de consentimento livre e esclarecido (TCLE) e questionário, que deveriam ser entregues aos professores de Educação Física e de Arte da escola. Após uma semana, aproximadamente, os questionários e os TCLE eram devolvidos para o pesquisador pelos responsáveis pela área pedagógica das escolas.

O período de realização do estudo ocorreu do início de março de 2011 a final de junho de 2015, refletindo a realidade específica desse período. Após a aplicação dos questionários, os dados coletados foram analisados através do cálculo dos percentuais obtidos nas respostas fechadas, utilizando o programa Excel for Windows. As informações recolhidas nas perguntas abertas do questionário foram interpretadas e sintetizadas para que ocorresse a análise dos conteúdos contidos nas mesmas, classificando, categorizando e interpretando os dados obtidos. Assim, a análise dos dados ocorreu através da determinação de duas categorias que têm relação com o objetivo do estudo, sendo estas: perfil do professor de dança: formação e capacitação; e, perfil do professor de dança: atuação na escola.

$\mathrm{Na}$ etapa final da pesquisa, realizamos um fechamento da análise dos dados, discutindo e chegando às considerações finais do trabalho, buscando traçar um perfil dos sujeitos estudados em relação à formação e capacitação em dança e identificar se eles trabalham com a dança no currículo escolar.

\section{PERFIL DO PROFESSOR DE DANÇA: FORMAÇÃO E CAPACITAÇÃO}

Os resultados obtidos nos questionários demostraram que $70 \%$ do total de sujeitos da pesquisa são mulheres (64 professoras) e $30 \%$ são homens (27

MORAES, Laura Ruaro; BEVILACQUA, Martina; ALVES, Taiana Souza; VALLE, Flávia Pilla do; HAAS, Aline Nogueira. Formação e capacitação em dança de professores de artes e educação física do Ensino Fundamental. Revista da FUNDARTE. Montenegro, p.01-17, ano 20, oㅡ 41, Abril/Junho de 2019.

Disponível em: http://.seer.fundarte.rs.gov.br/index.php/RevistadaFundarte/index> 30 de junho de 2020. 


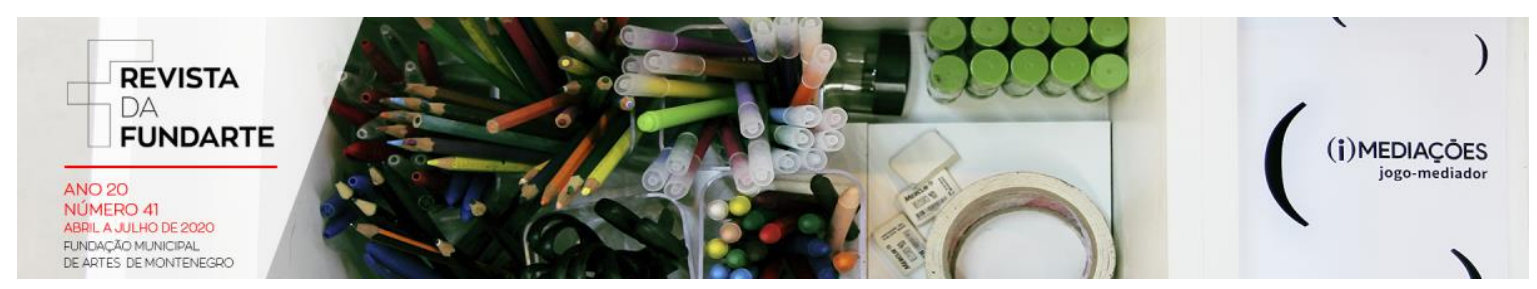

professores). Estes dados vêm ao encontro dos achados de Massutti (2003), no qual a maioria dos professores de Educação Física que ensinavam dança na Rede Municipal de Ensino Fundamental de Porto Alegre eram de sexo feminino, para um público quase exclusivamente feminino.

Sabemos que a presença da mulher na escola e na dança é predominante. Estudos de gênero têm discutido essa questão. Louro (2008, p.89) diz que "[...] a escola é atravessada pelos gêneros". Se por um lado, a escola é feminina, pois é marcada pelo cuidado, pela vigilância e pela educação, por outro lado o conhecimento da escola foi historicamente produzido pelos homens. A mesma autora chama a atenção que ao longo do século XIX, a entrada das mulheres na sala de aula vai ser "a" atividade permitida à elas que, pouco a pouco, tornam-se a maioria como docentes. Já na dança, o imaginário romântico do ballet no século XVIII que valoriza a mulher etérea e suave ainda parece interferir a representação do que é ser mulher na atualidade.

Em relação à formação específica na área da dança, obtivemos diferentes respostas. Dos 91 professores, 28 (31\% dos sujeitos) realizaram cursos livres na área da dança na educação não-formal, em escolas de dança; enquanto que $58 \%$ dos sujeitos, mais que a metade, não possuem cursos na área. Dentre os professores que possuem uma formação específica em dança foram elencadas áreas bem variadas, dentre estas: ballet clássico, jazz dance, dança contemporânea, sapateado, street dance e dança de salão. Dentre os cursos livres mais citados estão: Sapateado Americano, Jazz Dance, Danças Gaúchas, Ballet Clássico, Danças de Salão (pagode, salsa, samba de gafieira, forró), Danças Circulares, Dança do Ventre, Afros, Danças Urbanas, Dança Contemporânea, Danças Folclóricas, Flamenco, Contato Improvisação, Dança Criativa e Dança Moderna. Nesse sentido, Valle e Haas (2011) relataram que as primeiras manifestações de professores de dança, em Porto Alegre, tiveram sua formação em cursos livres em danças de vertente teatral.

MORAES, Laura Ruaro; BEVILACQUA, Martina; ALVES, Taiana Souza; VALLE, Flávia Pilla do; HAAS, Aline Nogueira. Formação e capacitação em dança de professores de artes e educação física do Ensino Fundamental. Revista da FUNDARTE. Montenegro, p.01-17, ano 20, n 41, Abril/Junho de 2019.

Disponível em: http://.seer.fundarte.rs.gov.br/index.php/RevistadaFundarte/index> 30 de junho de 2020. 


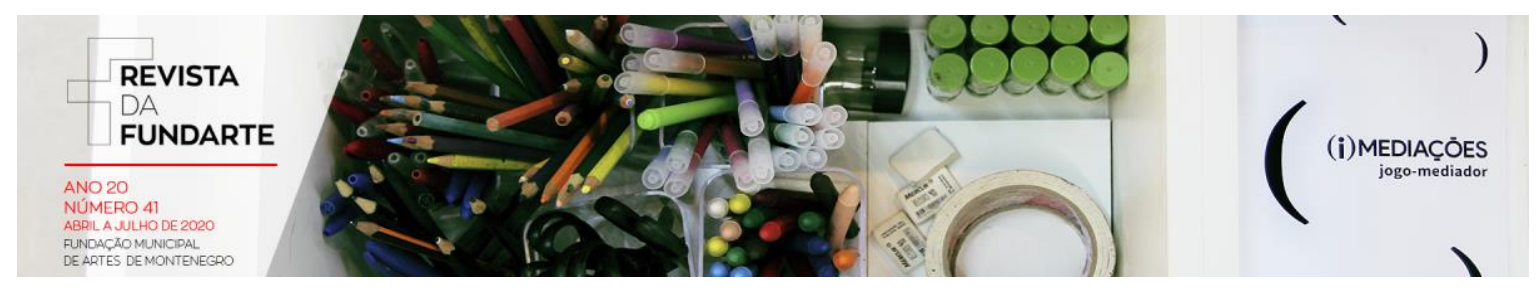

Há muitos anos o ensino da dança acontece em espaços de educação nãoformal, como as academias ou escolas de dança. Esses espaços são responsáveis pela formação dos principais nomes da dança no país e pela maioria dos que atum hoje na área. (MORANDI, 2006, p.105).

Atualmente, a partir do Plano Setorial de Dança (2005), é possível afirmar que existem dois caminhos para a profissionalização em dança: o ensino formal e o ensino não-formal (CONTREIRAS, 2012). Dentro do ensino formal encontram-se os Cursos de Graduação (Licenciatura e Bacharelado) e Tecnólogo em Dança, que são regulamentados pelo Conselho Federal de Educação e aprovados pelo Ministério de Educação e Cultura - MEC (WOSNIAK, 2010). Como ensino não-formal são considerados os cursos livres (cursos realizados em estúdios, academias, escolas, projetos, centros de formação), que não são reconhecidos pelo MEC. Nesse caso, o profissional poderá obter seu registro profissional junto aos SATED (Sindicato dos Artistas e Técnicos em Espetáculos de Diversões) e SINDIDANÇA (Sindicato de Dança, casos de São Paulo e Rio de Janeiro) comprovando sua atuação na área (TERRA, 2010).Os cursos livres buscam uma ênfase na formação do bailarino, pois a formação é dedicada à prática de passos e às técnicas de movimento; já, a universidade não se detém em determinado estilo e não submete o aluno a uma técnica específica, mas pretende ser um ambiente que enfoque o pensar a dança de forma crítica (VALLE; HAAS, 2011). Vale lembrar que a ênfase aqui colocada não é uma separação do pensar e fazer, uma vez que essas funções não acontecem em separado. Nesse sentido, Bergallo (2003, p.97) afirma:

Não só pensar e não só 'agir', mas a fusão ou a construção compartilhada entre os que pensam a teoria e aqueles que acumularam um capital inscrito em seus próprios corpos, possibilitando a aproximação entre a linguagem do 'movimento' sistematizada e a linguagem acadêmica.

Dessa forma, a universidade é um local onde os artistas terão a possibilidade de refletir, estudar e pesquisar sobre sua prática artística, além de desenvolver um diálogo com a sociedade, buscando um aprofundamento teórico-prático na área

MORAES, Laura Ruaro; BEVILACQUA, Martina; ALVES, Taiana Souza; VALLE, Flávia Pilla do; HAAS, Aline Nogueira. Formação e capacitação em dança de professores de artes e educação física do Ensino Fundamental. Revista da FUNDARTE. Montenegro, p.01-17, ano 20, oㅜ 41, Abril/Junho de 2019.

Disponível em: http://.seer.fundarte.rs.gov.br/index.php/RevistadaFundarte/index> 30 de junho de 2020. 


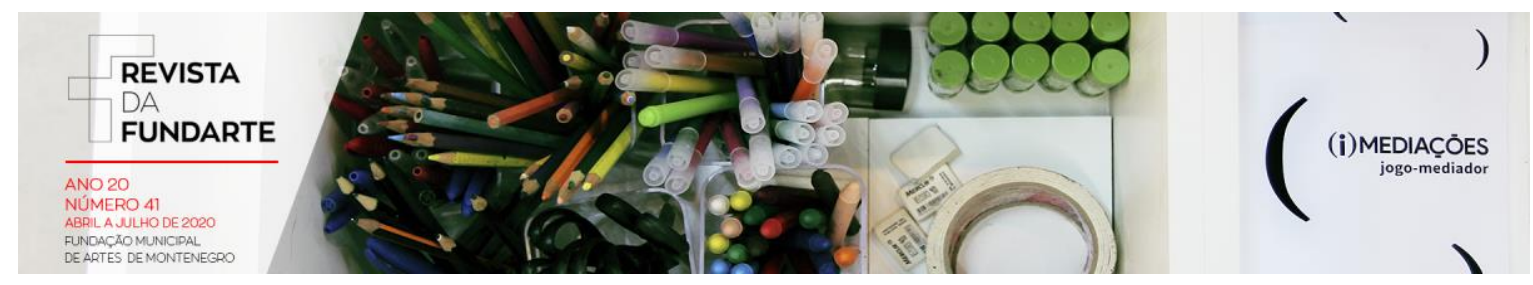

dança, podendo ser direcionado para a licenciatura ou bacharelado. Além disso, terão acesso a professores, doutores da área da dança, que poderão contribuir para sua formação e desenvolvimento enquanto profissional da área. Ambas trajetórias de formação realizadas pelos profissionais da dança, não-formal e formal, exercem grande importância neste processo, possuindo "funções específicas e diferenciadas, e porque não, articuláveis." (TERRA, 2010, p. 73).

Em relação à graduação dos sujeitos de pesquisa (Tabela 1), 55 eram formados em Educação Física (60\% do total); 35 em Artes (39\% do total); e, 1 indivíduo tinha formação em letras e literatura (1\% do total), mas atuava como professor na disciplina de Arte. Logo, no grupo dos sujeitos estudados não havia nenhum professor graduado em Dança. Morandi (2006, p.102) aponta que "muitos dançarinos, formados na tradição das escolas e academias, ao procurarem um curso superior, optam pela educação física". Essa realidade foi vivida pelos gaúchos, visto que, os cursos de graduação em dança são recentes e em pequena quantidade em relação às graduações em educação física. A autora continua seu argumento expondo que "a maioria dos profissionais de educação física que trabalham com dança nas escolas ou que se interessam mais especificamente pelo assunto, teve experiência com dança antes da graduação" (MORANDI, 2006, p.102103).

Portanto, até 2015, os egressos das Licenciaturas em Dança não ocupavam vagas na Rede Municipal de Porto Alegre pelo menos nas escolas que se disponibilizaram a participar desse estudo. Um fator importante que pode ter influenciado nesse resultado, é que os primeiros egressos do Curso de Licenciatura em Dança da UFRGS, universidade sediada em Porto Alegre, finalizaram o curso no final de 2012, se formando no início de 2013. Dessa forma, um ano e meio, após a formatura da primeira turma de egressos desse curso, pode não ter sido tempo suficiente para que esses profissionais se inserissem nas Escolas Municipais de Ensino Fundamental. Ressaltando, também, que, para que ocorresse essa inserção,

MORAES, Laura Ruaro; BEVILACQUA, Martina; ALVES, Taiana Souza; VALLE, Flávia Pilla do; HAAS, Aline Nogueira. Formação e capacitação em dança de professores de artes e educação física do Ensino Fundamental. Revista da FUNDARTE. Montenegro, p.01-17, ano 20, oㅡ 41, Abril/Junho de 2019.

Disponível em: http://.seer.fundarte.rs.gov.br/index.php/RevistadaFundarte/index> 30 de junho de 2020. 


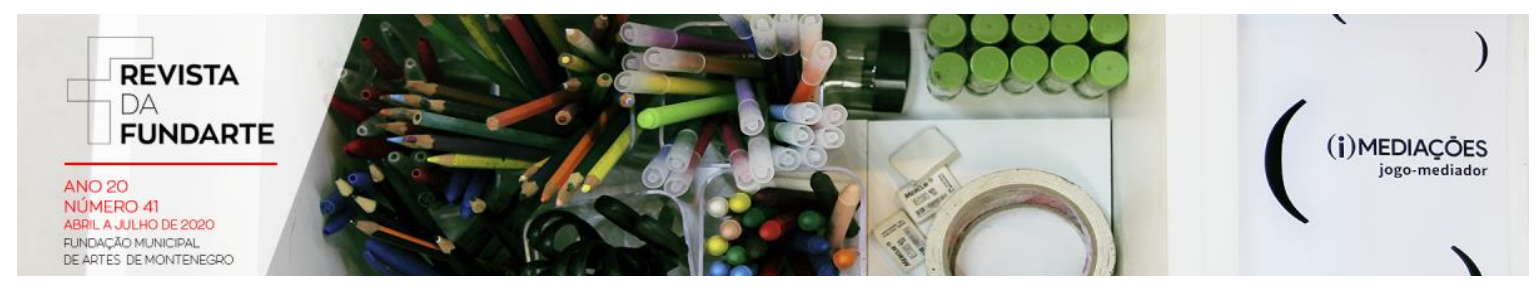

seria necessário a realização de cursos para a área e isso não ocorreu. Nos últimos dez anos, somente houve um concurso para ministrar o conteúdo de dança nas escolas no Município de Porto Alegre ${ }^{7}$ e um concurso para atuar como professor de dança no Estado do Rio Grande do Sul.

$\mathrm{Na}$ análise dos dados, também observou-se que dos 91 professores, somente 37 (41\% do total) tiveram disciplinas nas suas graduações que envolvessem conteúdos de dança em sua formação, sendo as mais citadas: rítmica dança, rítmica fundamentos, expressão corporal, análise e expressão rítmica, atividade rítmica escolar, dança folclórica, dança contemporânea, danças gaúchas, análise expressiva, técnicas de teatro e da dança, evolução do teatro e a dança. Porém, esses professores cursaram uma ou no máximo duas dessas disciplinas durante 0 seu curso de graduação, não sendo este conhecimento, muitas vezes, suficiente para que possam ministrar aulas de dança. Isso corrobora com o pensamento de Strazzacappa(2009), quando diz que a dança como conteúdo na escola formal é pouco abordada, muitas vezes, pela falta de especialistas da área ou pelo despreparo do professor que poderia vir a atuar na mesma. A seguir na Tabela 1 uma sistematização das formações de graduação dos sujeitos pesquisados.

Tabela 1 - Formação em Cursos de Graduação

\begin{tabular}{|c|c|c|c|}
\hline \multicolumn{2}{|c|}{ GRADUAÇÃO } & № SUJEITOS & PERCENTUAL (\%) \\
\hline \multirow{4}{*}{ ARTES } & Artes Plásticas & 20 & 22 \\
\cline { 2 - 4 } & Música & 6 & 7 \\
\cline { 2 - 4 } & Artes Cênicas & 5 & 6 \\
\cline { 2 - 4 } & Dança & 0 & 0 \\
\cline { 2 - 4 } & $\begin{array}{c}\text { Educação } \\
\text { Artística }\end{array}$ & 4 & 4 \\
\hline
\end{tabular}

${ }^{7} \mathrm{O}$ concurso para professor de dança no Município de Porto Alegre foi realizado no ano 2008. A escolaridade, exigências mínimas e/ou habilitação legal para o concurso foi licenciatura em dança ou licenciatura em educação física com curso de especialização (Pós-graduação) em dança.

MORAES, Laura Ruaro; BEVILACQUA, Martina; ALVES, Taiana Souza; VALLE, Flávia Pilla do; HAAS, Aline Nogueira. Formação e capacitação em dança de professores de artes e educação física do Ensino Fundamental. Revista da FUNDARTE. Montenegro, p.01-17, ano 20, oㅡ 41, Abril/Junho de 2019.

Disponível em: http://.seer.fundarte.rs.gov.br/index.php/RevistadaFundarte/index> 30 de junho de 2020. 


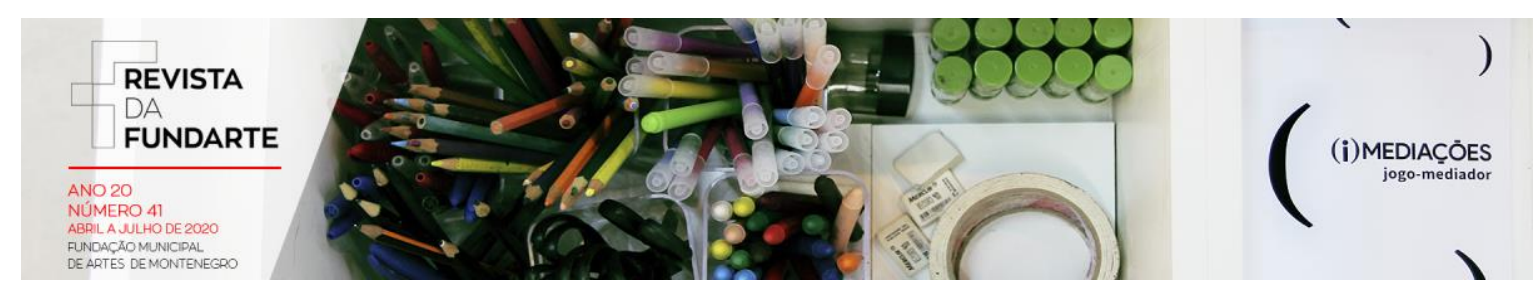

\begin{tabular}{|c|c|c|}
\hline TOTAL ARTES & 35 & 60 \\
\hline EDUCAÇÃO FÍSICA & 55 & 1 \\
\hline $\begin{array}{c}\text { OUTRAS ÁREAS (Letras e } \\
\text { Literatura) }\end{array}$ & 1 & \\
\hline
\end{tabular}

Em 1956, foi criado o primeiro curso de graduação em dança no Brasil, na Escola de Dança da Universidade Federal da Bahia (VALLE; HAAS, 2011). Somente em 1998, o primeiro curso superior de dança foi criado no Estado do Rio Grande do Sul, pela Universidade de Cruz Alta (UNICRUZ), sendo este no interior do Estado. $O$ Curso de Licenciatura em Dança da UNICRUZ funcionou durante onze anos, até ser fechado no ano de 2009, deixando de ofertar novas vagas. Somente, nos anos 2000 , os cursos superiores de dança chegaram a regiões próximas a Porto Alegre.

Atualmente, temos o seguinte panorama de universidades que oferecem cursos de graduações em dança no Estado do Rio Grande do Sul: Universidade Estadual do Rio Grande do Sul (UERGS, 2002), em Montenegro; Universidade Federal de Pelotas (UFPel, 2008), em Pelotas; Universidade Federal do Rio Grande do Sul (UFRGS, 2009), em Porto Alegre; Universidade Federal de Santa Maria (UFSM, 2013), em Santa Maria. Na UFSM é onde encontra-se o único curso de bacharelado em dança do RS. A Universidade Luterana do Brasil ofertou dança a partir de 2003 e formou a última turma em agosto de 2009, encerrando suas atividades. E por fim, no ano de 2014, foi criado o curso de Tecnólogo em Dança da Universidade de Caxias do Sul (PALUDO, 2015) mas que funcionou em poucas edições e já foi extinto. Assim, os cursos de graduação em Dança no Estado do Rio Grande do Sul, ainda são recentes, indo ao encontro ao resultado encontrado na Tabela 1, onde não encontramos nenhum individuo graduado em Dança. Observase também que os cursos nas universidades privadas oscilam sua oferta conforme a procura de alunos o que tem uma relação direta com a situação econômica do país.

Em relação a formação em nível de pós-graduação latu e stricto sensu, os

MORAES, Laura Ruaro; BEVILACQUA, Martina; ALVES, Taiana Souza; VALLE, Flávia Pilla do; HAAS, Aline Nogueira. Formação e capacitação em dança de professores de artes e educação física do Ensino Fundamental. Revista da FUNDARTE. Montenegro, p.01-17, ano 20, oㅡ 41, Abril/Junho de 2019.

Disponível em: http://.seer.fundarte.rs.gov.br/index.php/RevistadaFundarte/index> 30 de junho de 2020. 


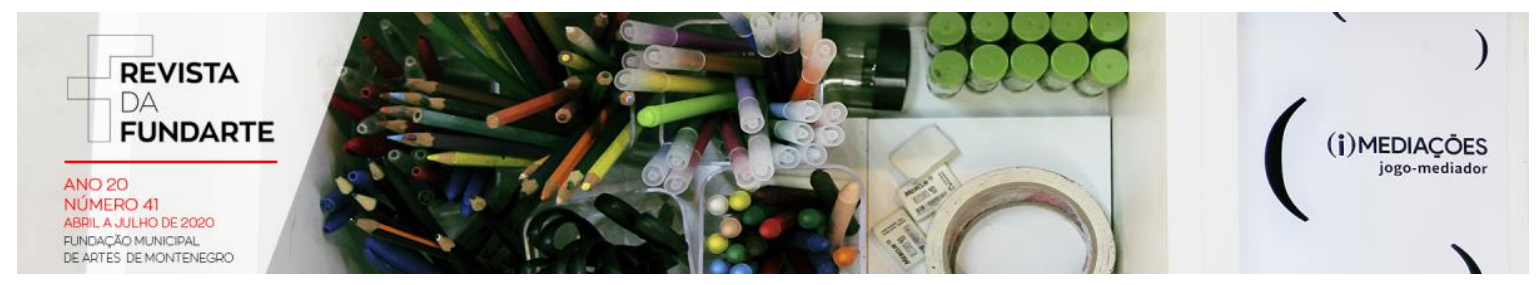

resultados apontam que 12 sujeitos (13\%) não possuem pós-graduação e 79 sujeitos ( $87 \%$ dos pesquisados) possuem pós-graduação em diversas áreas (Stricto Sensu e/ou Lato Sensu). Somente seis sujeitos ( $7 \%$ dos pesquisados) tem especialização em dança, sendo citados cursos de MBA em dança e o curso de especialização em dança da PUCRS. Nesse sentido, observa-se que a dança não é uma área de interesse principal para a maioria dos sujeitos que participaram do estudo.

Valle e Haas (2011) relataram que a PUCRS, em 2002, foi pioneira no cursos de Especialização em Dança na cidade de Porto Alegre. Em 2009, a UNIVATES lançou a Especialização em Dança; em 2010, a ULBRA; e, em 2015, a UFRGS. Assim, podemos perceber um aumento de cursos de especialização específicos na área, gerando um aumento de oferta de cursos no ensino formal. Essa oferta, entretanto, não é contínua e regular.

Apesar de Paludo (2015, p. 60) trazer que "o aumento significativo de cursos de graduação e pós-graduação nessa área [dança], no Brasil, ainda não são suficientes para a efetiva inserção do profissional Licenciado em Dança na escola", acreditamos que os novos cursos de graduação e pós-graduação que surgiram no Rio Grande do Sul nos últimos 10 anos, poderão proporcionar uma melhora na qualificação dos novos professores que trabalharão com dança nas escolas. Segundo Vargas (2011) os profissionais formados em curso superior de dança recebem instrumentos para conceber o ser humano em cinco dimensões: cognitiva, corporal, afetiva, ética e estética de relação intra e interpessoal e de inserção social, podendo qualificar sua atuação no mercado.

Assim, acreditamos que a abertura de vagas para concursos públicos em nível estadual e municipal, assim como, a contratação de professores Licenciados em Dança para atuar no âmbito das escolas privadas, se torna relevante para a inserção desse profissional, já que a LDB prevê a obrigatoriadade do ensino da arte/dança na escola como linguagem artística independente.

MORAES, Laura Ruaro; BEVILACQUA, Martina; ALVES, Taiana Souza; VALLE, Flávia Pilla do; HAAS, Aline Nogueira. Formação e capacitação em dança de professores de artes e educação física do Ensino Fundamental. Revista da FUNDARTE. Montenegro, p.01-17, ano 20, oㅡ 41, Abril/Junho de 2019.

Disponível em: http://.seer.fundarte.rs.gov.br/index.php/RevistadaFundarte/index> 30 de junho de 2020. 


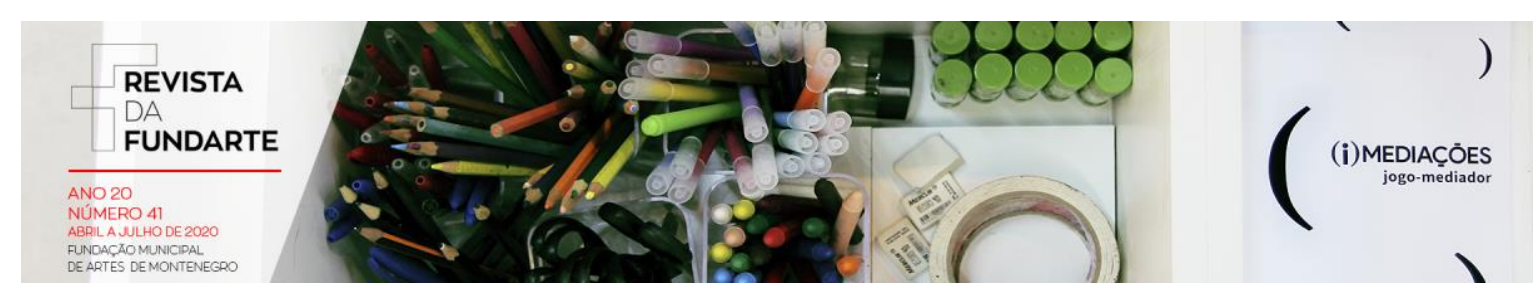

\title{
4 PERFIL DO PROFESSOR DE DANÇA: ATUAÇÃO NA ESCOLA
}

Em relação ao número de professores que atuam com dança nas suas aulas, verificamos que, dos 91 professores que participaram do estudo, 26 ( $29 \%$ do total) sentem-se capacitados para trabalhar com dança na escola, mas somente 19 (21\% do total) trabalham com a dança em sala de aula. Sendo assim, menos de um terço dos professores do total investigado se sentem capacitados e apenas em torno de um quinto trabalham com a dança.

Desse total dos professores que trabalham com a dança na escola, 6 são professores de artes e 13 são de educação física. Desse pequeno grupo de professores, 17 se sentem capacitados para ministrar atividades de dança; ou seja, dois dos professores ministram atividades de dança mas não se sentem capacitados para tal atividade, sendo ambos graduados em educação física. Morandi nos fala sobre sua realidade que pode ser justaposta neste caso quando aborda:

\begin{abstract}
Os cursos de graduação em educação física dão um enfoque restrito ao conteúdo de dança em comparação aos outros conteúdos da área. Com apenas uma disciplina semestral os alunos não se sentem aptos para tratar desse conhecimento na escola. A realidade dos cursos de formação tem reflexo direto na educação básica. Como esperar que algo pouco desenvolvido, como o conteúdo de dança, possa ser bem trabalhado? (MORANDI, 2006, p.102)
\end{abstract}

Constatamos que os professores que se sentem capacitados para ministrar o conteúdo de dança, em algum momento, tiveram na sua formação cursos livres de dança, ou ainda, uma ou duas disciplinas relacionadas à área na sua graduação; e, duas professoras, possuem pós-graduação em nível lato e stricto senso.

Para Marques (2003) a formação de professores que atuam na área de dança é um dos pontos mais críticos no que diz respeito ao ensino dessa arte no sistema escolar. Na prática, tanto os professores de Educação Física como os de Arte, vêm trabalhando com dança nas escolas, sem, muitas vezes, buscarem conhecimentos

MORAES, Laura Ruaro; BEVILACQUA, Martina; ALVES, Taiana Souza; VALLE, Flávia Pilla do; HAAS, Aline Nogueira. Formação e capacitação em dança de professores de artes e educação física do Ensino Fundamental. Revista da FUNDARTE. Montenegro, p.01-17, ano 20, oㅡ 41, Abril/Junho de 2019.

Disponível em: http://.seer.fundarte.rs.gov.br/index.php/RevistadaFundarte/index> 30 de junho de 2020. 


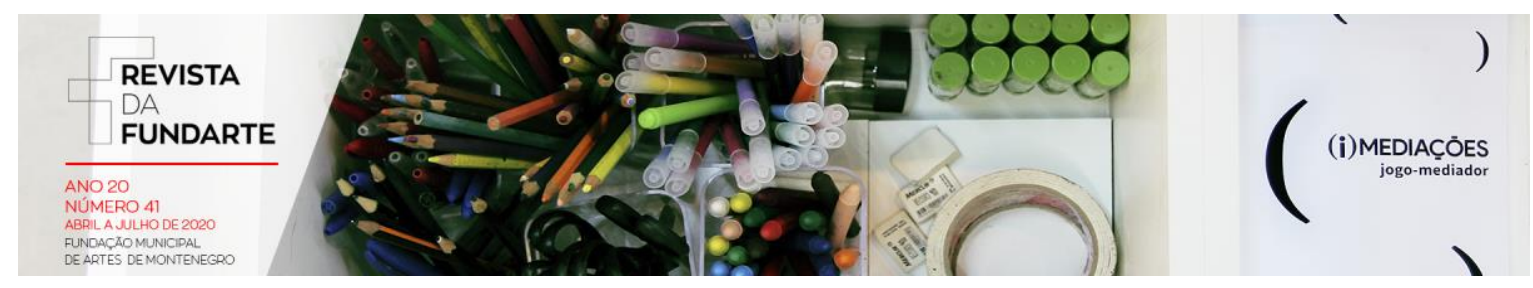

teórico-práticos também como intérpretes, coreógrafos e diretores de dança, limitando-se somente a seus aspectos pedagógicos. Por outro lado:

[...] ao pensarmos sobre a função da arte na escola como articulação de linguagem e forma de conhecimento, entendemos que os voluntários, os artistas, os bem intencionados em geral, não deveriam ocupar o lugar do professor de Arte, que é um profissional da Educação. (MARQUES e BRAZIL, 2012, p.47).

Por não se querer apenas um licenciado e nem um artista, é que acreditamos que a graduação em dança em nível de licenciatura proporcionaria um conhecimento mais aprofundado para exercer a docência-artista da dança.

Silva e Schwartz (2000/1, p. 52) ao refletirem sobre a formação do professor que deve atuar com dança na escola, afirmam:

\begin{abstract}
pode-se perceber que a atualização do profissional, o conhecimento teórico específico, a fundamentação e embasamento a respeito da clientela a ser atingida, as formas mais eficientes de ensino, a aplicação do conteúdo correto, entre outras variáveis, representam fatores essenciais para o desenvolvimento competente e significativo do ensino da dança.
\end{abstract}

Duarte (1995, apud PACHECO, 1998 - 1999) também recorre ao argumento da deficiência na formação profissional, além dos preconceitos sociais em relação à prática de dança pelo sexo masculino, para explicar o número reduzido de educadores que trabalham com dança nas escolas.

\title{
4 CONSIDERAÇÕES FINAIS
}

Após a análise dos dados, é possível traçar um perfil quase comum em relação à formação e capacitação dos professores das Escolas Fundamentais de Ensino Fundamental de Porto Alegre, RS que trabalham com dança de Arte e Educação Física; e, com isso refletir sobre os déficits em sua formação para o ensino da dança na escola. Os sujeitos de pesquisa possuem uma formação frágil na área da dança, pois dificilmente têm contato com a mesma, tanto nas suas

MORAES, Laura Ruaro; BEVILACQUA, Martina; ALVES, Taiana Souza; VALLE, Flávia Pilla do; HAAS, Aline Nogueira. Formação e capacitação em dança de professores de artes e educação física do Ensino Fundamental. Revista da FUNDARTE. Montenegro, p.01-17, ano 20, oㅜ 41, Abril/Junho de 2019.

Disponível em: http://.seer.fundarte.rs.gov.br/index.php/RevistadaFundarte/index> 30 de junho de 2020. 


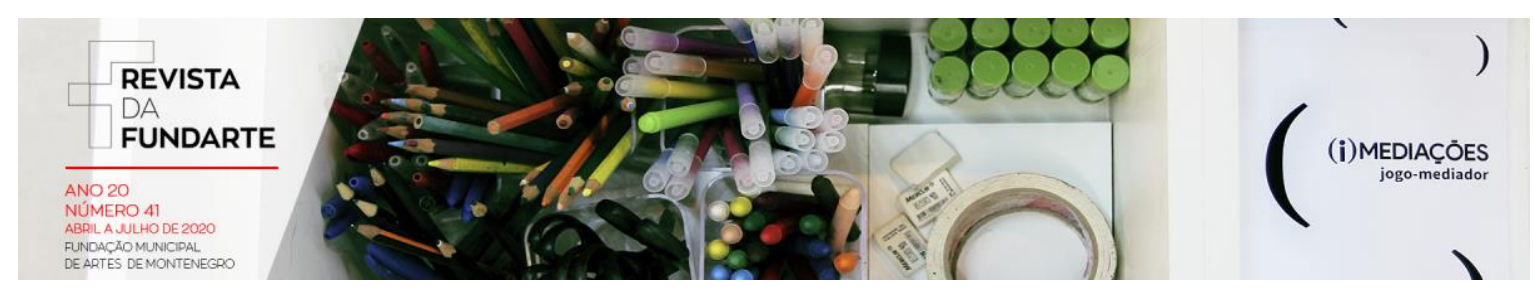

graduações ou fora delas em nível de cursos livres. Assim, não se sentem, na sua maioria, capacitados para trabalhar com esse conteúdo nas suas aulas.

Os resultados obtidos refletiram uma realidade específica de uma época, demonstrando que os egressos de licenciaturas em dança ainda não estavam inseridos no ensino fundamental de escolas municipais de Porto Alegre. Fato esse ocorrido provavelmente pelo pouco número de formados em cursos de dança no Estado do Rio Grande do Sul e pela pouca oferta de concursos para magistério até então.

Acreditamos que essa área necessita ser inserida na escola de forma mais efetiva, refletindo sobre a importância de trabalhar esse tipo de conteúdo com os alunos, já que a LDB prevê o ensino da dança como obrigatório.

Com o aumento do número de cursos de graduação em dança no Rio Grande do Sul e no Brasil, nas duas últimas décadas, a formação em nível superior passa a ser uma opção. Assim, consideramos importante que o professor responsável pela dança na escola seja licenciado nesta área e busque, constantemente, um aprimoramento, para que ocorra um ensino de qualidade. Dessa forma, a dança poderá se inserir nas escolas de forma relevante quanto aos demais trabalhados na área das artes.

\section{Referências:}

BERGALLO, Andréa. Graduação em Dança: contradições e reflexões sobre legitimidade e hegemonia. In: CALAZANS, Julieta; CASTILHO, Jacyan; GOMES, Simone (coord.). Dança e educação em movimento. São Paulo: Cortez, 2003.

BRASIL, 1997. Parâmetros Curriculares Nacionais. Secretaria de Educação Fundamental. Brasília: MEC/SEF. 1997.

BRASIL, 1996. Lei de Diretrizes e Bases (LDB). Disponível em:

$<$ http://www.presidencia.gov.br/ccivil_03/Leis/L9394.htm>. Acesso em: 07 de março de 2017.

Brasil, 2007. Ministério da Educação. REUNI. Disponível em: http://reuni.mec.gov.br.

MORAES, Laura Ruaro; BEVILACQUA, Martina; ALVES, Taiana Souza; VALLE, Flávia Pilla do; HAAS, Aline Nogueira. Formação e capacitação em dança de professores de artes e educação física do Ensino Fundamental. Revista da FUNDARTE. Montenegro, p.01-17, ano 20, oㅜ 41, Abril/Junho de 2019.

Disponível em: http://.seer.fundarte.rs.gov.br/index.php/RevistadaFundarte/index> 30 de junho de 2020. 


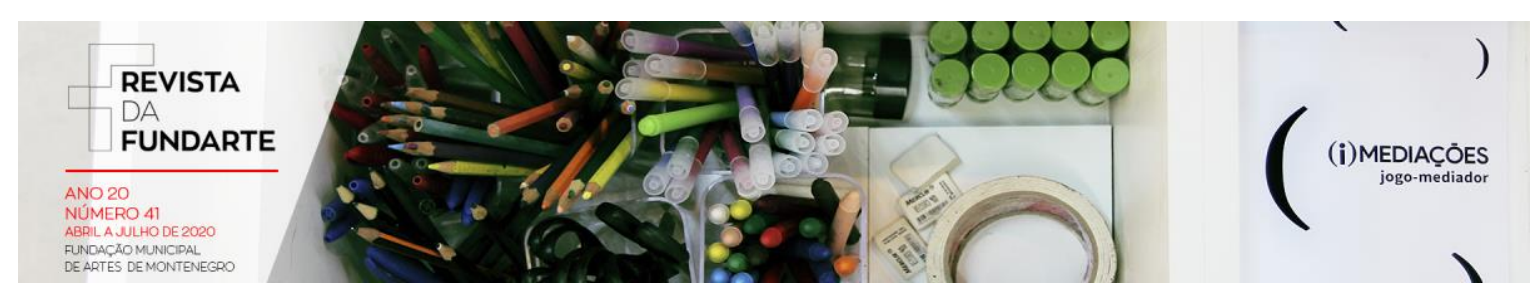

Acesso em: 07 de março de 2017

BRASIL, 2016. Lei no 13.278, de 2 de maio de 2016. Disponível em: <http://www.planalto.gov.br/ccivil_03/_ato2015-2018/2016/lei/13278.htm>. Acesso em: 07 de março de 2017.

BRASIL, 2017. Base Nacional Comum Curricular (BNCC). Disponível em; http://basenacionalcomum.mec.gov.br/images/pdf/1_BNCC-Final_Introducao.pdf . Avesso em: 17 de maio.2017.

CONTREIRAS, Clarice Nunes Muniz. Mercado de trabalho e perfil profissional: egressos da Escola de Dança.2012. 80 f. Dissertação (Mestrado) - Escola de Dança da Universidade Federal da Bahia. Salvador, 2012.

GAYA, Adroaldo (org.). GARLIP, Daniel ... [et. al.]. Ciências do movimento humano: Introdução à metodologia da pesquisa. Porto Alegre: Artmed, 2008

LOURO, Guacira Lopes. Gênero, sexualidade e educação: uma perspectiva pósestruturalista. 10ª edição. Rio de Janeiro: Vozes, 2008. 180p.

MARQUES, I. Dançando na Escola. São Paulo: Cortez, 2003. 197 p

MARQUES, Isabel; BRAZIL, Fábio. Arte em questões. São Paulo: Digitexto, 2012. $176 p$.

MASSUTTI, S. M. A dança como conteúdo de Educação Física nas Escolas da Rede Municipal de Porto Alegre. 2003. Monografia (Curso de Especialização em Dança) - Faculdade de Educação Física e Ciências do Desporto, Pontifícia Universidade Católica do Rio Grande do Sul, Porto Alegre, 2003. 47 f.

MORANDI, Carla. O descompasso da dança e da educação física. In: STRAZZACAPPA, Márcia; MORANDI, Carla. Entre a arte e a docência: a formação do artista da dança. S/ao Paulo: Papirus, 2006.

PACHECO, A. J. P. Educação Física e dança: uma análise bibliográfica. Pensar a Prática 2, Jun./Jun, 156-171,1998-1999.

PALUDO, Luciana. O lugar da coreografia nos cursos de graduação em dança do Rio Grande do Sul, Brasil. 241 f. Tese (Doutorado) - Faculdade de Educação da Universidade Federal do Rio Grande do Sul, Porto Alegre, 2015.

SILVA, M. G. M. S. da; SCHWARTZ, G. M. Por um ensino significativo da dança.

MORAES, Laura Ruaro; BEVILACQUA, Martina; ALVES, Taiana Souza; VALLE, Flávia Pilla do; HAAS, Aline Nogueira. Formação e capacitação em dança de professores de artes e educação física do Ensino Fundamental. Revista da FUNDARTE. Montenegro, p.01-17, ano 20, n 41, Abril/Junho de 2019.

Disponível em: http://.seer.fundarte.rs.gov.br/index.php/RevistadaFundarte/index> 30 de junho de 2020. 


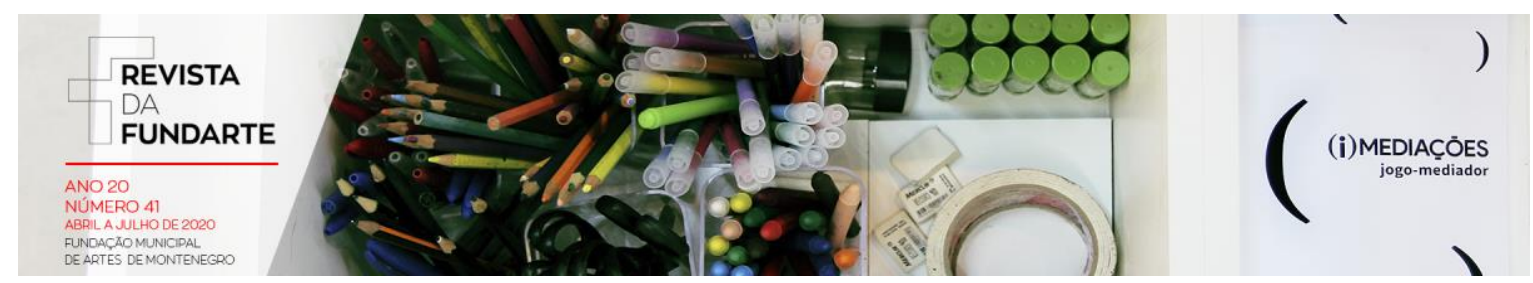

Revista Movimento. Ano VI. № 12. 2000/1. p. 45 - 52.

SOUZA, João Batista Lima de; PEREIRA, Marcelo de Andrade; ICLE, Gilberto. Entre arte e docência: Um estudo sobre o perfil de egressos dos cursos de graduação em dança no Sul do Brasil. Arquivos Analíticos de Políticas Educativas, Arizona, v. 77, n. 23, p.1-26, ago. 2015. Disponível em: <http://dx.doi.org/10.14507/epaa.v23.1789>. Acesso em: 04 set. 2015.

STRAZZACAPPA, Márcia. Dançando na Chuva... e no Chão de Cimento. In: FERREIRA, Sueli (Org.). O Ensino das Artes: construindo caminhos. 7. ed. Campinas: Papirus, 2009. P. 39-78.

TERRA, Ana. Onde se produz o artista da dança? In: TOMAZZONI, Airton; WOSNIAK, Cristiane; MARINHO, Nirvana. Alguma perguntas sobre Dança e Educação. Seminários de Dança. Joinville: Nova Letra, 2010.p. 67-76.

THOMAS, J. R.; NELSON, J. K.; SILVERMAN, S. J. Métodos de pesquisa em atividade física. 6. ed. Porto Alegre: Artmed, 2012.

VALLE, Flavia Pilla do; HAAS, Aline Nogueira. Formação em dança no Rio Grande do Sul e sua interface com a pesquisa. Revista da FUNDARTE. Montenegro. ano 11, no 21, p.22 - 25.

VARGAS, Lisete Arnizaut. Formação em Dança, para quê? Nossa experiência na UFRGS. In: I Congresso da Associação Nacional de Pesquisadores em Dança ANDA. 2011, São Paulo. Anais... São Paulo: 1ª Ed., p. 69-81, 2011.

WOSNIAK, Cristiane. Bacharelado e/ou licenciatura: quais são as opções do artista da dança no Brasil? In: TOMAZZONI, Airton; WOSNIAK, Cristiane; MARINHO, Nirvana. Alguma perguntas sobre Dança e Educação. Seminários de Dança. Joinville: Nova Letra, 2010.p. 121-123.

MORAES, Laura Ruaro; BEVILACQUA, Martina; ALVES, Taiana Souza; VALLE, Flávia Pilla do; HAAS, Aline Nogueira. Formação e capacitação em dança de professores de artes e educação física do Ensino Fundamental. Revista da FUNDARTE. Montenegro, p.01-17, ano 20, oㅜ 41, Abril/Junho de 2019.

Disponível em: http://.seer.fundarte.rs.gov.br/index.php/RevistadaFundarte/index> 30 de junho de 2020. 